\title{
Could Meaning in Life Contribute to Adolescents' Vocational Commitment and Identity? A Longitudinal Analysis in Different Chinese Cultures
}

\author{
Mengting Li, ${ }^{1}$ Weiqiao Fan, ${ }^{1}$ Fanny M. Cheung, ${ }^{2}$ and Qian Wang ${ }^{2}$ \\ ${ }_{1}^{1}$ Research Institute for International and Comparative Education, and Department of Psychology, Shanghai Normal University, \\ Shanghai, China \\ 2 Department of Psychology, The Chinese University of Hong Kong, Hong Kong, China
}

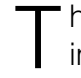
his longitudinal study investigated the contributions of Chinese secondary school students' meaning in life in Grade 10 to vocational identity in Grade 12 in different Chinese settings. Whether vocational exploration and commitment reported by students (VECS) in Grade 11, and the vocational exploration and commitment reported by parents (VECP) of the students mediate the above link was examined as well. Participants comprised 435 students and their parents/guardians from Hong Kong, 422 students and their parents/guardians from urban Shanghai, and 308 students and their parents/guardians from rural Zhejiang. Partial mediation of the VECS in the relationship between meaning in life and vocational identity was significant in the Shanghai and Zhejiang rural samples. In the Hong Kong sample, the VECP was significantly predicted by meaning in life and could predict vocational identity. Associations between parental perceptions of vocational commitment and adolescents' own career development might therefore be weaker than previously believed. The pattern of the relationships between meaning in life, vocational commitment and identity, and the influence of parents on adolescents' career development in different Chinese local contexts are discussed herein.
\end{abstract}

Keywords: meaning in life, vocational commitment, vocational identity, Chinese adolescents, parents

Vocational identity, as one core aspect of adolescent identity development (Erikson, 1968), has been defined by Holland, Gottfredson, and Power (1980) as 'the possession of a clear and stable picture of one's goals, interests, and talents' (p. 1191). Savickas (1985) argued that vocational identity is related to both vocational development and ego identity formation and that it forms the basis upon which students crystallise tentative career preferences. Vocational identity was also empirically documented as one of the most important outcome variables of career development for facilitating adolescents' transition from school to work and contributes to one's adjustment and wellbeing (Meijers, 1998; Mortimer, Zimmer-Gembeck, Holmes, \& Shanahan, 2002).

Building on the contributions made by personenvironment (P-E) fit and social cognitive career theory (SCCT; Lent, Brown, \& Hackett, 1994) to explore the antecedents of vocational identity becomes one key domain for understanding and improving adolescents' career development. As such, both distal factors, such as personality traits, parenting style and cultural milieu, and proximal factors, such as vocational interest, career self-efficacy and commitment in which individuals are raised, may, in part, guide the process of identity formation (Crocetti, Rubini, Luyckx, \& Meeus, 2008; Holland, Johnston, \& Asama, 1993).

However, in modern/postmodern societies, career is about more than fitting one's personality with a particular environment and job tasks. Individuals, especially adolescents, must explore who they are and what their purpose is, and understand their strengths and skills in order to truly develop a satisfying career, and even establish a meaningful life (Guichard, 2015; Kosine, Steger, \& Duncan, 2008; Mayseless \& Keren, 2014; Savickas, 2013). Recently, the paradigm of career construction has focused on increasing the meta-competencies of adaptability and identity and the meaning-making of projective stories (Savickas, 2013). Before adolescents establish a vocational identity, they thus need to explore and assess various alternatives (Marcia, 1966), construct their meaning in life, and are

This study was supported by National Social Sciences Found of China, 14BSH081, and the Hong Kong Government Research Grants Council Earmarked Grant The GRF Grant 2012/13, CUHK 441812.

Address for correspondence: Weiqiao Fan, Research Institute for International and Comparative Education, and Department of Psychology, Shanghai Normal University, Shanghai 200234, China. Email: fanweiqiao@shnu.edu.cn 
considered responsible for the direction their personal and professional lives will take (Guichard, 2015). However, the role of meaning in life among adolescents' career development has often been neglected (Kosine et al., 2008).

Vocational identity is an integral part of the process of personal identity formation and provides the framework for meaning within which adolescents assume agentic control over their vocational development. Orientation toward the future and a propensity for planning play a major role in adolescents' vocational exploration and the subsequent choices they make (Ferrari, Nota, \& Soresi, 2010). Adolescents who explore future opportunities and find personal meaning are more likely to engage in exploratory behaviours and achieve a vocational identity. Future planning and the inclination to seek meaning in life are often considered to be attributes associated with maturity. This general disposition toward meaning in life therefore contributes to adolescents' vocational identity through a process of vocational exploration and commitment. Vocational commitment is often referred to as the progression from a phase of indecision, through sufficient exploration, to a highly committed phase (Blustein, Ellis, \& Devenis, 1989). Theoretically, it may reflect a psychological state between the subject and a certain objective (Allen \& Meyer, 1990). Blustein et al. (1989) further found that adolescents who are more certain about their ego identity are more likely to be committed to their career choices.

Therefore, integrating the progress of career construction theory and SCCT in the field of vocational psychology, the present study examined potential associations between meaning in life as a cognitive personality trait, and vocational identity in adolescent students from three different Chinese regional settings with a multicultural perspective. At the same time, the mediated effect of vocational commitment on the link between meaning in life and vocational identity was examined from a developmental perspective.

\section{Meaning in Life and Career Development}

Steger (2009) argued that meaning in life conceptually consists of two pillars: comprehension and purpose. Comprehension refers to an individual's capacity to find modes, consistency, and significance in those events and experiences in their lives; while purpose encompasses highly motivating, long-term goals about which people are passionate and highly committed. As such, meaning in life is assumed to be cognitive in nature (Ho, Cheung, \& Cheung, 2010). In addition, Wong (1998) also argued that the cognitive dimension of meaning in life includes beliefs that there is an ultimate purpose in life, beliefs in moral laws, and beliefs in an afterlife (see also Ho et al., 2010). Meaning in life reflects individuals' differences in organising and interpreting their experience, achieving a sense of their own worth and place, identifying the things that matter to them, and effectively directing their energies and even self-fulfillment (Ho et al., 2010; Ryff \& Singer, 1998; Steger, 2009; Yu, Chang, \& Kim, 2016).

Meaning in life has been increasingly documented as having significant associations with important careerrelated constructs among different adult populations (e.g., employees and college students), such as career calling (Duffy \& Dik, 2013; Zhang, Hirschi, Herrmann, Wei, \& Zhang, 2017), career adaptability (Buyukgoze-Kavas, Duffy, \& Douglass, 2015), career decision-making efficacy (Pesch, Larson, \& Seipel, 2018), vocational outcome expectations and goals (Bhattacharya, 2011; Pesch et al., 2018), and vocational commitment (De Klerk, 2003).

In adolescence (mainly in the middle-school period), individuals start to explore their career interests (Super, 1980) and gradually construct their cognitive map of occupations (Gottfredson, 2002) and vocational identity (Vondracek \& Porfeil, 2003). A success in these career tasks can lay a foundation of adolescent vocational maturity and performance in adulthood (Hartung, 2013). Therefore, the associations between career development and meaning in life among adolescents should not be neglected. However, explorations of the influence of meaning in life on career development and satisfaction among adolescents are largely sparse in literature (Kosine et al., 2008), with a few of exceptions. For example, a recent study of Hong Kong Chinese adolescents (Yuen \& Yau, 2015) found that meaning in life significantly predicted career adaptability. In another study, Yeager and Bundick (2009) reported that American adolescents with purposeful work goals also reported more meaning in life than those who did not.

For adolescents, the middle-school period (generally aged 12-18 years old), which Erikson (1968) employed to characterise the powerful crossroads of identity versus role confusion, is a time when they begin a lifelong search for personal meaning. Particularly, this meaning in life may help adolescents deal with the major developmental task of forming a coherent sense of self, represented by their collective identity, a mental picture rooted in personal experience and that reflects a wide compendium of cultural, social, community, and family forces (Crocetti et al., 2008). In other words, the significant relationship between meaning in life and vocational identity is very worthwhile for adolescents to explore.

\section{Present Study}

Consistent with the understanding by Ho et al. (2010), in this study we also conceptualised meaning in life as a cognitive personality trait, because it is primarily rooted in human cognition and reflects individuals' differences in comprehending life experiences and being motivated to achieve life objectives, and their outlook about their whole life. The operationalisation of meaning in life is having meaningful goals and motives for personal identity and goal striving (Ho et al., 2010). From the perspective of SCCT, meaning in life is defined as one personality trait and should be a distal factor to individuals' career 
development (Lent et al., 1994). Alternatively, because the construct of meaning in life reflects people's patterns to personalise their life events and experiences in terms of their purposes in life, and because it is the product of social interaction and co-constructed outcome through thinking and discourse, to explore the associations between meaning in life and career development simultaneously performs the paradigm of career construction (Savickas, 2013).

Before adolescents commit to a vocational identity, they thus need to explore and assess various alternatives (Marcia, 1966), construct their meaning in life, and become responsible for the direction their personal and professional lives will take (Guichard, 2015). Based on the abovementioned empirical evidence, meaning in life contributes to an individual's career development and reflects their concerns related to career identity. For example, Frankl (1992) argued that people actualise creative, experiential and attitudinal values within their lives, and these are imbued with meaning through constructing vocational identity. Accordingly, personal meaning in life helps individuals to develop a vocational direction, make choices, and to regulate their personal development during critical life transitions (Salmela-Aro, 2009).

Beyond personal attributes, the formation of vocational identity also involves a series of person-context interactions. For adolescents, parents constitute a major part of this developmental process (Beyers \& Goossens, 2007). For example, Bryant, Zvonkovic, and Reynolds (2006) explored the various parenting processes that influence adolescents' vocational development, including their occupational knowledge and attitudes, exploration aspirations, and self-efficacy. It is commonly believed that parents influence this process by being accessible to their children and becoming involved in their activities. In so doing, they transmit their knowledge about the world of work, set aspirations and expectations regarding their children's academic and occupational futures, and provide tangible assistance in terms of resources. The parental variables adopted in previous studies include parental background and psychological characteristics, their involvement with children's developmental activities, and the level of guidance and support they provide. Relevant to the vocational development process, parental views may also affect their children's career choices (Michael, Cinamon, \& Most, 2015). This may be particularly true in Asian cultures, where parents exert a more direct influence on their children's development; thus, it is generally presumed that parental views are closely associated with children's vocational outcomes (Sawitri, Creed, \& Zimmer-Gembeck, 2015).

Silbereisen, Vondracek, and Berg (1997) argued that the importance of contextual factors such as sociocultural background and parental support is associated with vocational exploration, commitment, and career choices in adolescence. Modernisation in Asian societies has meant that the vocational landscape has become more complex and access to information more diversified. In this changing social context, it is pertinent to ask whether parents know the status of their children's vocational development and whether an understanding of children's commitment affects their vocational identity. This research adopted a longitudinal perspective to address the role played by parental perceptions, secondary school students' vocational commitment, and student meaning in life in the development of vocational identities. Furthermore, meaning in life has been assumed to predict vocational commitment (De Klerk, 2003), which has also been perceived as a partial mediator between career barriers and vocational identity (Urbanaviciute, Pociute, Kairys, \& Liniauskaite, 2016). Therefore, based on existing evidence demonstrating associations between some individual attributes and vocational identity (e.g., Hirschi, 2011, 2012; Li, Fan, Cheung, \& Wang, in press), Hypothesis 1 in this study was set as follows: Chinese adolescents' vocational commitment and their parents' perception of this commitment mediates the contribution from meaning in life to vocational identity.

Culture plays a multifaceted role in career development that is unique to each individual (Young, Marshall, \& Valach, 2007). In studies of Chinese psychology, a common criticism has been that the Chinese culture is not uniform and instead varies according to socioeconomic development within a specific region (e.g., Kwan, Bond, Boucher, Maslach, \& Gan, 2002). To test this proposition, our study included samples recruited from three different regions of China: Hong Kong and Shanghai, both of which are more economically developed cities, and a rural region in Zhejiang (close to Shanghai), in responding to growing calls for research concerning culture to pay due attention to within-culture variations (see Kagitcibasi, 2007). Hong Kong is a special administrative region of China with its own system of finance and education carried over from its legacy as a British colony. According to the World Bank, its per capita GDP in 2017 was USD48,848, significantly higher than the national Chinese figure of USD9,482 (World Bank, 2017). By comparison, Shanghai is a fastgrowing city in China and its per capita GDP in 2017 was USD18,749 (National Bureau of Statistics of China, n.d.). In 2012, Shanghai students surpassed all other countries to be ranked first in mean scores for mathematics, reading and science in the OECD Program for International Student Assessment (PISA; OECD, 2012). Hong Kong came second in both reading and science and third in mathematics. The rural region in Zhejiang is less economically developed than Shanghai. No statistics are available for this rural region; however, as an eastern coastal region, the overall economic development of the province of Zhejiang is reflected in a per capita GDP that exceeds the national average. Compared with the cosmopolitan cities of Hong Kong and Shanghai, more traditional Chinese cultural values and education concepts and practices are maintained in rural regions (e.g., Jiang \& Zhang, 2009; Li \& Jia, 2012; Li, Zhu, \& Feldman, 2004; Ma, 2017; Min 


\begin{tabular}{|c|c|c|c|c|c|c|}
\hline \multirow[b]{2}{*}{ Educational level } & \multicolumn{2}{|c|}{ Hong Kong } & \multicolumn{2}{|c|}{ Shanghai } & \multicolumn{2}{|c|}{ Zhejiang rural region } \\
\hline & Mother & Father & Mother & Father & Mother & Father \\
\hline Primary & 14.83 & 16.18 & 2.26 & 2.50 & 16.39 & 15.67 \\
\hline Secondary & 66.99 & 61.76 & 33.33 & 29.00 & 57.19 & 54.33 \\
\hline Postsecondary & 9.09 & 7.84 & 33.08 & 32.00 & 19.40 & 18.67 \\
\hline Tertiary or higher & 9.09 & 14.21 & 31.33 & 36.50 & 7.02 & 11.34 \\
\hline
\end{tabular}

\& Chen, 1991). The different socioeconomic context of the three locations provided further insights into regional variations within the Chinese culture.

Thus, given the influence of sociocultural context on adolescents' career development (Cheung, Wan, Fan, Leong, \& Mok, 2013; Li et al., in press; Silbereisen et al., 1997), we explored regional variations in the pattern of relationships investigated in Hypothesis 1. Hypothesis 2 was set as follows: The pattern of relationship investigated in Hypothesis 1 should be moderated by region (Hypothesis $2 a$ ), and specifically, the rural regions of Zhejiang province are more traditional and thus parental perceptions of vocational commitment might be associated more strongly with children's vocational development (Hypothesis 2b).

\section{Method}

This study was a part of a 3-year longitudinal study on adolescent career development that was conducted in three Chinese locations since 2013. The relevant data were collected from adolescents in Grade 10, Grade 11, and Grade 12. All data collections were conducted in the first semester of the corresponding grade. Therefore, the interval between two data collections was 1 year, and the whole longitudinal study lasted 2 years, with a three-wave data collection.

\section{Participants and Procedure}

Four high schools of different academic standing in Hong Kong, two high schools in Shanghai, and one high school in the Zhejiang rural region were invited to participate. The students from the Zhejiang rural region were from typical families in the Zhejiang countryside. Incentives to participate included a school report summarising the students' vocational development profile. Individual students were also promised personality and vocational development profiles at the end of the longitudinal study, at which point they will have reached Grade 12.

At Grade 10, 435 Hong Kong students $(53.13 \%$ females; $\left.M_{\text {age }}=16.31, S D=.65\right)$, 422 Shanghai students $\left(56.87 \%\right.$ females; $\left.M_{\text {age }}=16.49, S D=.55\right)$, and 308 Zhejiang students $\left(61.36 \%\right.$ females; $\left.M_{\text {age }}=16.39, S D=.53\right)$ agreed to participate with the consent of their parents. Furthermore, 258 parents of Hong Kong students, 372 parents of Shanghai students, and 245 parents of Zhejiang students gave their consent and returned the completed questionnaire. The distribution of the educational level of the parents was reported in Table 1.

At Grade 11, 371 (85.29\%) Hong Kong students, 378 (89.57\%) Shanghai students, and 257 (83.44\%) Zhejiang students completed the second wave of data collection. At Grade 12, 354 (81.38\%) Hong Kong students, 226 (53.55\%) Shanghai students, and 173 (56.17\%) Zhejiang students completed the third wave of data collection. Attrition analyses showed that there was no difference in research variables at Grade 10 between those participants who finished all three wave data collection and those who missed data collection at Grade 11 and/or Grade 12.

\section{Instruments}

Meaning in life. The Cross-ultural (Chinese) Personality Inventory for Adolescents (CPAI-A; Cheung, Cheung, \& Fan, 2013; Fan, Cheung, Cheung, \& Leung, 2008) was developed to assess intrapersonal and interpersonal personality dimensions using a combined etic-emic approach. The CPAI-A (Form B) consists of four factors encompassing 25 personality scales: (1) Social Potency/Expansiveness, (2) Dependability, (3) Emotional Stability, and (4) Interpersonal Relatedness. The subscale of Life Goal is one dimension of the Dependability factor and measures the degree to which adolescents think about and seek meaning in life (Ho et al., 2010). A high score on the scale is indicative of an individual who has clear comprehension of one's life modes, consistency and significance in terms of their life experiences, may have developed clear life purposes, ambitions and motivations to spend time on things that add value to life, and may have developed a life philosophy. It comprises 10 items in a yes/no response format. For example, one item states that 'I make good use of my time after school to learn different things so as to enrich my life'. In terms of internal consistency, Fan et al. (2008) reported that the Cronbach's alpha for the scale was .76. The data of meaning in life (as one subscale of the CPAI-A) was only collected at Grade 10 in the current study. The Cronbach's alpha for the subscale is reported in Table 2.

Vocational exploration and commitment. The Vocational Exploration and Commitment (VEC) subscale of the Commitment to Career Choices Scale (Blustein et al., 1989) was employed to investigate participants' level of commitment to their vocational choices. The same instrument was then adapted to assess parental perceptions of 
Table 2

Descriptive Statistics for Meaning in Life, VEC and Vocational Identity

\begin{tabular}{|c|c|c|c|c|c|c|c|c|c|c|c|}
\hline & \multicolumn{6}{|c|}{ Region } & \multicolumn{2}{|c|}{ Gender } & \multirow{3}{*}{$\begin{array}{l}\text { Total } \\
M(S D)\end{array}$} & \multirow{3}{*}{$\begin{array}{l}F^{\#} \\
(d f 2,451)\end{array}$} & \multirow{3}{*}{$\begin{array}{l}F^{\# \#} \\
(d f 1,451)\end{array}$} \\
\hline & \multicolumn{2}{|c|}{ Hong Kong } & \multicolumn{2}{|c|}{ Shanghai } & \multicolumn{2}{|c|}{ Zhejiang } & \multirow{2}{*}{$\frac{\text { Female }}{M(S D)}$} & \multirow{2}{*}{$\frac{\text { Male }}{M(S D)}$} & & & \\
\hline & $\mathrm{M}(S D)$ & $\alpha$ & $M(S D)$ & $\alpha$ & $M(S D)$ & $\alpha$ & & & & & \\
\hline $\mathrm{ML}_{\text {Grade } 10}$ & $6.32(2.49)$ & .72 & $7.02(2.19)$ & .72 & $6.25(2.38)$ & .70 & $6.85(2.27)$ & $6.15(2.47)$ & $6.55(2.38)$ & $4.37^{*}$ & $4.11^{*}$ \\
\hline VECS $_{\text {Grade10 }}$ & $3.82(.72)$ & .88 & $4.13(.83)$ & .87 & $3.94(.90)$ & .88 & $3.96(.83)$ & $3.97(.81)$ & $3.96(.82)$ & $7.94^{* *}$ & .71 \\
\hline VECS $_{\text {Grade11 }}$ & $3.84(.72)$ & .89 & $4.06(.78)$ & .85 & $3.95(.75)$ & .88 & $3.92(.77)$ & $3.98(.74)$ & $3.95(.76)$ & $4.57^{*}$ & 2.49 \\
\hline $\mathrm{VECP}_{\text {Grade10 }}$ & $4.04(.65)$ & .86 & $4.16(.71)$ & .85 & $4.13(.70)$ & .81 & $4.12(.71)$ & $4.12(.68)$ & $4.12(.69)$ & 1.02 & .27 \\
\hline $\mathrm{VECP}_{\text {Grade11 }}$ & 4.07 (.67) & .74 & $4.14(.66)$ & .83 & $4.04(.75)$ & .82 & $4.10(.70)$ & 4.09 (.67) & 4.09 (.69) & 1.53 & 1.11 \\
\hline $\mathrm{VI}_{\text {Grade 10 }}$ & $7.21(4.51)$ & .86 & 8.73 (4.68) & .86 & $7.19(4.19)$ & .83 & 7.91 (4.51) & $7.53(4.53)$ & 7.75 (4.54) & $9.38^{* *}$ & .04 \\
\hline $\mathrm{VI}_{\mathrm{Grade} 2}$ & $8.51(4.82)$ & .87 & $8.81(4.68)$ & .85 & $8.35(4.47)$ & .83 & $8.80(4.77)$ & 8.35 (4.74) & $8.57(4.75)$ & .56 & 1.71 \\
\hline
\end{tabular}

Note: $\mathrm{ML}=$ meaning in life, $\mathrm{VI}=$ vocational identity, $\mathrm{VECS}=$ vocational exploration and commitment reported by students, $\mathrm{VECP}=$ vocational exploration and commitment reported by parents of the students. ${ }^{\#} F$ test examined regional differences in the corresponding variables, ${ }^{\# \#} F$ test examined gender differences in the corresponding variables. The corresponding group differences for the means in bold type were significant.

$* p<.05,{ }^{* *} p<.01$.

their children's vocational commitment. The VEC (Blustein et al., 1989) consists of 19 items that 'tap an individual's perceived level of self-knowledge, occupational knowledge, confidence about, and overall commitment to a specific occupational preference, as well as the perceived need to engage in career exploration, uncertainty with regard to career choices, and awareness of and willingness to overcome potential obstacles' (p. 349). In this study, participants rated the items on a 7-point Likert scale ranging from 1 (almost always untrue about me) to 7 (almost always true about me). A high score on the VEC indicates higher commitment. We used the Chinese version of the VEC translated by Jin, Watkins, and Yuen (2009), which was found to have good internal consistency reliability (.82). The VEC was completed by students and their parents in Hong Kong, Shanghai, and Zhejiang at both Grade 10 and Grade 11. The corresponding Cronbach's alphas the VEC in the study are reported in Table 2.

Vocational identity. We used the Vocational Identity (VI) subscale of the My Vocational Situation Scale (MVS; Holland et al., 1993) to assess participants' career identity. Vocational identity refers to the possession of a clear and stable sense of one's goals, interests, and talents. The VI subscale consists of 18 items in a true/false response format and is scored in terms of the total number of false answers given (after reversing the direction of four items). A high VI score indicates 'a clear sense of identity' and a low VI score indicates 'a diffuse sense of identity' (p. 1194). High VI scorers were found to be independent, well-organised, self-confident, mature, and capable of handling their lives competently. Holland et al. (1980) reported that the reliability (K-R 20) of the VI was .86 for both male and female high school students. In the present study, the MVS was administrated to students at Grade 10 and Grade 12. The corresponding Cronbach's alphas are reported in Table 2.

In addition to the vocational measures, we collected demographic information on students' age, gender, and year of study, and the parents' age and educational level.
All measures were administrated to participants in the Chinese language.

\section{Data Analysis}

A multivariate analysis of variance (MANOVA) was used to examine gender and regional differences among these variables. A partial correlation analysis was then conducted to examine the pattern of relationships among the research variables with gender as control variable. Mplus (Version 7.4) was used to examine the testing models. Missing data were handled in Mplus using full information maximum likelihood (FIML) estimation. The SEM bias-corrected bootstrapping approach $(n=5,000)$ of mediation test was used in this study.

\section{Results}

\section{Descriptive Statistics and Gender/Regional Differences}

The means and standard deviations of all the variables are presented in Table 2. A MANOVA was employed to examine the overall effects of gender and region and their interaction on meaning in life, vocational exploration and commitment reported by students (VECS), and the vocational exploration and commitment reported by parents (VECP) of the students, and vocational identity. The results showed there were main effects of both gender, Wilks' $\Lambda=.96, F(7,445)=2.93, p<.01, \eta^{2}=.04$, and region, Wilks' $\Lambda=.92, F(14,890)=2.74, p<.01, \eta^{2}=.04$. No significant interaction was found (see also Table 2).

Further univariate analyses indicated that the females scored higher meaning in life than did the males. A higher mean score of meaning in life was produced by Shanghai students than by students from Zhejiang. Shanghai students yielded the higher score than Hong Kong and Zhejiang students in vocational identity at Grade 10. Regarding vocational commitment, the VECS scores of the Shanghai students were significantly higher than those from Hong Kong at both Grade 10 and Grade 11. Furthermore, there was no significant regional difference in vocational commitment reported by parents. 
Table 3

Partial Correlations Among Meaning in Life, VEC and Vocational Identity After Controlling for Gender

\begin{tabular}{|c|c|c|c|c|c|c|c|c|c|c|c|c|c|}
\hline & 1 & 2 & 3 & 4 & 5 & 6 & 7 & 1 & 2 & 3 & 4 & 5 & 6 \\
\hline 1. $\mathrm{ML}$ at Grade 10 & - & $.45^{* *}$ & $.36^{* *}$ & .13 & .09 & $.49 * *$ & $.36 * *$ & - & & & & & \\
\hline 2. VECS at Grade 10 & $.61^{* *}$ & - & $.53^{* *}$ & $.24^{* *}$ & $.38^{* *}$ & $.68^{* *}$ & $.52^{* *}$ & $.58^{* *}$ & - & & & & \\
\hline 3. VECS at Grade 11 & $.48^{* *}$ & $.68^{* *}$ & - & .09 & $.49^{* *}$ & $.53^{* *}$ & $.60^{* *}$ & $.42^{* *}$ & $.52^{* *}$ & - & & & \\
\hline 4. VECP at Grade 10 & $.30 * *$ & $.35^{* *}$ & $.37^{* *}$ & - & $.17^{*}$ & $.25^{* *}$ & $.16^{*}$ & $.24^{* *}$ & $.32^{* *}$ & $.27^{* *}$ & - & & \\
\hline 5. VECP at Grade 11 & $.26^{* *}$ & $.31^{* *}$ & $.39 * *$ & $.57^{* *}$ & - & $.30 * *$ & $.35^{* *}$ & $.32^{* *}$ & $.35^{* *}$ & $.39 * *$ & $.49^{* *}$ & - & \\
\hline 6. VI at Grade 10 & $.60^{* *}$ & $.76^{* *}$ & $.60 * *$ & $.36^{* *}$ & $.40^{* *}$ & - & $.63^{* *}$ & $.59^{* *}$ & $.72^{* *}$ & $.55^{* *}$ & $.24^{* *}$ & $.33^{* *}$ & - \\
\hline 7. VI at Grade 12 & $.46^{* *}$ & $.57^{* *}$ & $.68^{* *}$ & $.37^{* *}$ & $.42^{* *}$ & $.69^{* *}$ & - & $.33^{* *}$ & $.41^{* *}$ & $.60^{* *}$ & .16 & $.34^{* *}$ & $.54^{* *}$ \\
\hline
\end{tabular}

Note: $\mathrm{ML}=$ meaning in life, $\mathrm{VI}=$ vocational identity, $\mathrm{VECS}=$ vocational exploration and commitment reported by students, $\mathrm{VECP}=$ vocational exploration and commitment reported by parents of the students. On the left side, correlations of the Hong Kong sample are shown below the diagonal line and correlations of the Shanghai sample are shown above the diagonal line. On the right side, the correlation matrix is for the Zhejiang rural sample.

${ }^{*} p<.05,{ }^{* *} p<.01$.

\section{Mediation Effects of Vocational Commitment on the Relationship Between Meaning in Life and Vocational Identity}

As shown in Table 3, significantly positive correlations among all research variables were largely supported across three samples with the exception of non-significant correlations between meaning in life and VECP at both Grades 10 and 11, between VECS at Grade 11 and VECP at Grade 10 in the Shanghai sample; and between VECP at Grade 10 and vocational identity at Grade 12 in the Zhejiang sample.

We then examined whether both VECS and VECP at Grade 11 significantly mediated the relationship between students' meaning in life at Grade 10 and vocational identity at Grade 12 with Mplus 7.4. Specifically, we tested three mediation models for the Hong Kong, Shanghai, and Zhejiang rural samples after controlling for both VECS and VECP and vocational identity at Grade 10. Within-time correlations were permitted. Meanwhile, gender and parental educational level were also included as control variables. The final models (Figure 1) deleted the non-significant paths of control variables. The fit of final models for Hong Kong $\left(\chi^{2}=57.52, d f=19\right.$, CFI $=$ .94 , RMSEA $=.070$, SRMR $=.080)$, Shanghai $\left(\chi^{2}=55.36\right.$, $d f=18, \mathrm{CFI}=.92, \mathrm{RMSEA}=.072$, SRMR $=.064)$, and Zhejiang $\left(\chi^{2}=61.19, d f=23, \mathrm{CFI}=.93\right.$, RMSEA $=.075$, SRMR $=.071)$ samples were adequate with respect to all fit indices.

As shown in Figure 1, meaning in life positively predicted VECP, and both VECS and VECP positively predicted vocational identity in the Hong Kong sample. As for the Shanghai sample, positive effects were found from meaning in life to VECS and from VECS to vocational identity. In the Zhejiang rural sample, meaning in life positively predicted both VECS and VECP, and VECS positively predicted vocational identity.

However, the bootstrap results indicated that, at a 95\% confidence level, the mediation effect of VECP on the link from meaning in life to vocational identity was nonsignificant in the Hong Kong sample (indirect effect: .02, $S E=.01,95 \%$ CI $[-.01, .04])$. Significant mediation effect of VECS on the link from meaning in life to vocational identity was found in Shanghai (indirect effect: .07, $S E=.02,95 \% \mathrm{CI}[02, .11])$ and Zhejiang rural (indirect effect: .06, SE $=.03,95 \% \mathrm{CI}[.01, .12])$ samples. Therefore, Hypothesis 1 was partly supported in the Shanghai and Zhejiang rural samples.

We also conducted multigroup analyses to test whether the mediation model was significantly moderated by region. The results, $\Delta \chi^{2}(52)=78.29, p<.05, \Delta \mathrm{CFI}=$ $-.02, \triangle \mathrm{RMSEA}=.004$, indicated that the unconstrained model in which parameters were free to vary across groups was significantly different from the constrained model in which the parameters were fixed across groups. Therefore, Hypothesis $2 \mathrm{a}$ was supported and the pattern of the mediation model varied in the three samples; however, even though the path from meaning in life to VECP was significant in the Zhejiang rural sample, we cannot derive the conclusion to support Hypothesis $2 \mathrm{~b}$.

\section{Discussion}

As with the important contributions that have documented meaning in life in career development in adult populations across cultures (e.g., Buyukgoze-Kavas et al., 2015; De Klerk, 2003; Duffy \& Dik, 2013; Pesch et al., 2018), and as predicted, meaning in life in this study was strongly associated with vocational commitment and identity for Chinese adolescents in all three regions, with some cross-cultural variations. This is consistent with previous studies (De Klerk, 2003; Blustein et al., 1989; Ferrari et al., 2010) that found that Western participants who search for meaning in life are more future-oriented and more likely to take the initiative when exploring their life options. Through their engagement in career exploration activities and their willingness to overcome potential obstacles and commit to their goals, they are more likely to achieve a clearer sense of vocational identity. The strong relationship between vocational commitment and vocational identity found in previous research on young people and adolescents (e.g., Orkibi, 2010; Shoffner \& Newsome, 2001) was also confirmed in this research.

According to Blustein et al. (1989), occupational knowledge and confidence, and an overall commitment to a specific occupational preference, are important dimensions of vocational commitment. Given the special period of career development undertaken by secondary school 


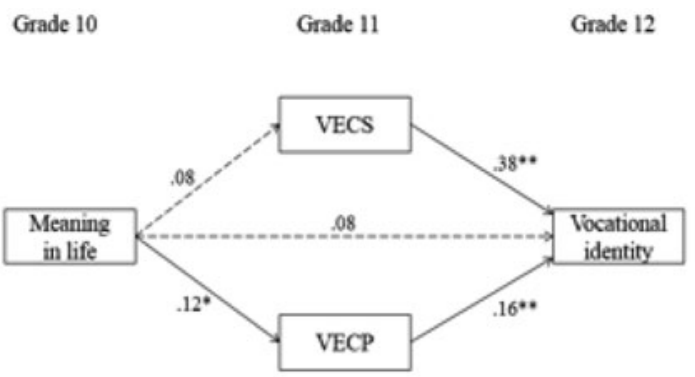

A. Hong Kong sample

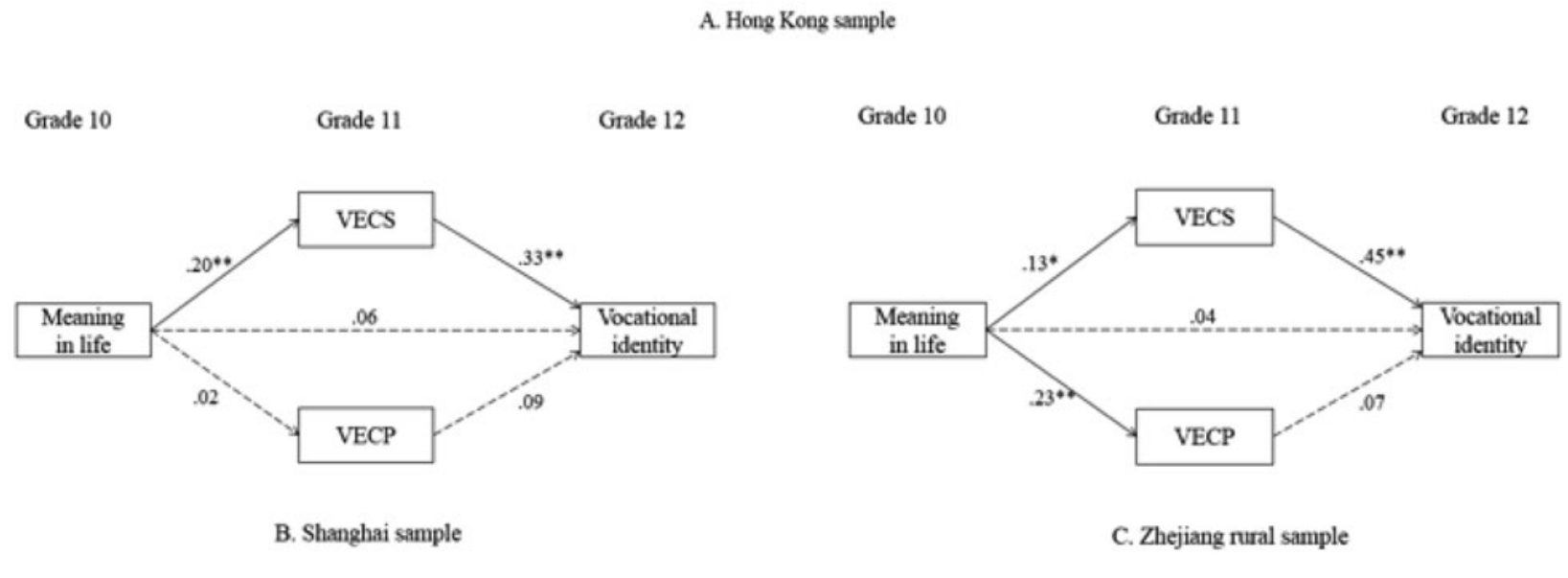

Figure 1

Mediation model of vocational commitment on the association between meaning in life and vocational identity

Note: VECS = vocational exploration and commitment reported by students, VECP $=$ vocational exploration and commitment reported by parents of the students. For model clarification, the effects of control variables (gender, parental educational level, and baseline level of VECS, VECP, and vocational identity) were not presented. Non-significant paths are indicated by a broken line. ${ }^{*} p<.05,{ }^{* *} p<.01$.

students, their vocational commitment should consist of academic satisfaction, and this was found to be a partial mediator in the perceived career barriers-vocational identity link (Urbanaviciute et al., 2016). Consistently, students' vocational commitment in the present study also displayed significant mediation effects on the contributions from meaning in life to vocational identity in the Shanghai and Zhejiang rural samples.

Longitudinal research conducted by Negru-Subtirica, Pop, and Crocetti (2015) showed that career adaptability (including career concern, control, curiosity, and confidence) and vocational identity are dynamic and interrelated dimensions of adolescent career development. Career adaptability may therefore predict adolescents' vocational identity over time. Savickas and Porfeli (2012) argued that career concern may refer to planning how to achieve one's career goals or life meaning while career control may refer to taking responsibility for one's career exploration actions. Therefore, given the longitudinal design in our study, the results further confirmed the relationships between meaning in life and adolescent vocational identity in Chinese contexts, albeit only to a certain extent. Furthermore, vocational commitment is also a pivotal factor in the construction of Chinese adolescents' vocational identity, particularly from a developmental perspective.
Our research shows that, even for students who have clear life meaning in an earlier period (e.g., Grade 10), if they do actively explore career options and engage in the process of vocational commitment during their studies (e.g., Grade 11), it may become easier to establish their vocational identity at a later stage of their career development (e.g., Grade 12). Therefore, vocational commitment might play a transformational role for adolescents from meaning in life through to vocational identity. The current findings also cross-validated the significant influences of meaning in life on career adaptability among Hong Kong Chinese adolescents reported by Yuen and Yau (2015) and the contributions of meaning in life to purposeful work goals among American adolescents reported by Yeager and Bundick (2009).

Family environment and relationships, especially relationships with parents, are important factors influencing adolescents' career expectations and development, particularly when they are in primary and secondary education (Duck et al., 2013). From the perspective of family dynamics, we originally hoped to examine parental perceptions of secondary students' career and commitment, and corresponding mediation effects between meaning in life and vocational identity in Chinese settings. However, even though significant correlations between VECP and student meaning in life, VECS, and vocational identity 
were well supported, the predicted effect of VECP was significant only in the Hong Kong sample, but not in the other two samples from mainland China. Particularly, this result was inconsistent with our Hypothesis $2 \mathrm{~b}$.

In the research literature, positive associations have been demonstrated between a clear and stable vocational identity and specific family-relevant factors such as family cohesion (Puffer, 1999), family interaction (Hartung, Lewis, May, \& Niles, 2002), and family expressiveness (Arcement, 2015). However, the connection between parental perceptions of adolescents' vocational commitment and vocational identity may not be as strong as previously believed for Chinese high school students, even in the more traditional adolescents from rural areas. Changing socioeconomic development in mainland China may have ameliorated the culturally traditional parental influence, particularly in a more complex vocational landscape. This generation of adolescents has become more independent in their decision making and may seek different sources of information and utilise other resources. Parents may have less access to information on career opportunities than their children's schools, peers, and the internet.

In terms of the influence of the birth control policy in mainland China, most of the students (88\%) in the Shanghai sample were only children. The corresponding figures were $27 \%$ in the Hong Kong sample and $63 \%$ in the Zhejiang rural sample. According to studies on only children in China (e.g., Wu \& Xu, 2014), although parents may pay close attention to their children, the children tend to act independently (Wang, Oakland, \& Liu, 1992; Xin, Zhou, Bray, \& Kehle, 2003) and parents generally try not to intervene. Communication between parents and an only child has often been found to be ineffective (Hao \& Wang, 2009). Parents might not really understand their child's life meaning or vocational expectations. Consequently, views on their children are likely to be one-sided, and no longer have such a strong effect on students' vocational identity.

One obvious consequence of the social transformation that has taken place in mainland China since 1978 is that its citizens, such as the parents in this study, attain a higher level of education. Compared with the higher proportion of the parents from Shanghai, only a few of the parents in the Hong Kong sample had received tertiary-level education (see Table 1). However, although the mediation effect between meaning in life and vocational identity needs to be further confirmed, that VECP could be predicted by meaning in life and could predict vocational identity suggests that VECP should be very particular in the research model in Hong Kong sample. One the one hand, this may suggest that a higher educational level among parents does not necessarily mean a higher level of parent-child communication. Previous studies have shown that an effective parent-child relationship and good communication is very beneficial to adolescents' career development (Pizzorno, Benozzo, Fina, Sabato, \& Scopesi, 2014). Rapid economic development has meant that parents in mainland China need to spend more hours working and thus have less time to spare to spend with their children, even in the rural area of Zhejiang. Moreover, many of the Zhejiang participants were boarders in school. Thus, parent-child communication among this group was limited as well.

In our study, most of the mothers in Hong Kong were housewives and these were the parents who reported their perceptions of their children's VEC. The role of a stayat-home mother may lead to a more intimate motherchild relationship, which may then promote the significant connections that we found for parental perceptions of VEC with students' meaning in life and vocational identity. Of course, these observations should be further explored in future research.

\section{Theoretical Contributions and Practical Implications}

Even though Shanghai students to some extent produced significantly higher scores for meaning in life, vocational commitment, and vocational identity than participants from Hong Kong and Zhejiang, the pattern of relationships between meaning in life, vocational exploration and vocational identity were largely supported among Chinese adolescents, with some regional variations. On the one hand, a longitudinal link from meaning in life to vocational identity through vocational commitment suggests that having a clear life meaning is a particularly important factor in adolescents' career development (Diemer \& Blustein, 2007). Hirschi (2011) argued that vocational identity may be achieved through high self-exploration, high commitment, confidence, and engagement in a career. In other words, if adolescents are well resourced to conduct career exploration, their meaning in life may contribute to their career development. On the other hand, the mediation effect of parental perceptions of children's vocational exploration and commitment was not supported across the three samples. Thus, the process of modernisation and socioeconomic development may mean that the traditional influence of parents on adolescents' vocational development may have diminished. This might be due to inadequate parent-child communication or the fact that adolescents' own social maturity and vocational exploration now play a stronger role in the formation of their vocational identity.

Given the rapid socioeconomic development of Chinese societies, increased attention has been paid to the role of career development education, guidance and services in facilitating secondary students' readiness for lifelong development (Fan \& Leong, 2016). Chinese societies are collectively controlled and relatively closed contexts; collective culture and interpersonal relatedness and family orientation are also characteristics highlighted in the literature in relation to adolescent career intervention and counselling (Cheung, Fan, \& Yao, 2012). Hesketh and Rounds (1995) argued that individuals from a collective culture are inclined to view career identity as a personal project that is fostered through group membership. 
However, the influences of parental perceptions of adolescent vocational commitment on Chinese adolescent vocational identity were not well supported, with an exception in the Hong Kong sample. Therefore, family-relevant issues relating to adolescent career identity development and career intervention should be carefully reconsidered in Chinese cultural settings.

Even though traditional Confucianism maintains a strong foothold in Chinese societies and may contribute to adolescents' career development, economic globalisation and the rapid advancement of information technology now means that Chinese adolescents are also exposed to Western cultural values in their everyday lives. Consequently, a cultural-values conflict and cultural orientation might influence the interaction between parents and adolescents and thus influence the process of career development. The effects of Confucian relational ethics (e.g., filial piety) on individuals, particularly young people and adolescents, in terms of how to fulfill their parents' expectations, obey their wishes, realise their individual life meaning, and maintain interpersonal harmony are increasingly challenging for these populations. At the same time, it is also difficult for Chinese parents to strike a balance between imparting family-related considerations and expectations on the one hand and providing vital and meaningful support to Chinese adolescents on the other (Young, Valach, Ball, Turkel, \& Wong, 2003).

In addition, in consideration of the regional differences of educational concepts, career education should also be strengthened in Chinese urban and rural regions. For example, in some studies (e.g., Li \& Jia, 2012; Ma, 2017) comparing the rural-urban differences in family education, Chinese urban parents were perceived to have warmer parenting styles than did their counterparts from rural regions, and more significant controlling styles were reported as well. Accordingly, educating parents from both urban and rural regions on their roles in children's career development (e.g., as supporters, not controllers) and in communicating with their children might also form an important component of career guidance for Chinese adolescents.

\section{Limitations and Future Directions}

There were three points of limitations in the present study, which might suggest fruitful directions for future research. First, although the current study was a three-wave longitudinal design that lasted 2 years from 10th grade to 12 th grade among Chinese secondary school students, this period of time was insufficient for deriving a causal relationship, and the data of some research variables (e.g., meaning in life) could not be collected in all three waves due to the workload of participants. Furthermore, some reciprocal associations among the research variables may exist and need to be examined systematically. Therefore, future longitudinal studies should continue exploring the changing pattern of adolescents' meaning in life, vocational com- mitment, and vocational identity over a longer timeframe with a more focused research project. Second, other reported measures should be employed in a future study. Adolescent career development is often an outcome of interactions between adolescents and their circumstances (e.g., parents, peers, and teachers; Yung et al., 2003). Although self-reports on meaning in life, vocational commitment, and vocational identity have been widely used in previous studies, integrating objective indicators and reports provided by people of influence (e.g., parents, teachers, and friends) could have strengthened the current findings. Third, the present study examined senior high school students in three Chinese local settings. However, the current patterns may be distinctive to these cities due to different regional cultures, economic and educational resources, particular career education, and interventions for adolescents. Thus, a thorough understanding of the associations among meaning in life, vocational commitment, and vocational identity of Chinese adolescents should examine more representative regions with different localised cultures in China.

\section{References}

Allen, N.J., \& Meyer, J.P. (1990). The measurement and antecedents of affective, continuance and normative commitment to the organization. Journal of Occupational Psychology, $63,1-18$.

Arcement, D.G. (2015). An investigation of the relationships among the family of origin, need for achievement, and career development (Order No. AAI3580367). Available from PsycINFO (1660462710; 2015-99041-150).

Beyers, W., \& Goossens, L. (2007). Dynamics of perceived parenting and identity formation in late adolescence. Journal of Adolescence, 31, 165-184.

Bhattacharya, A. (2011). Meaning in life: A qualitative inquiry into the life of young adults. Psychological Studies, 56, 280288. doi:10.1007/s12646-011-0091-0

Blustein, D.L., Ellis, M.V., \& Devenis, L.E. (1989). The development and validation of a two-dimensional model of the commitment to career choices process. Journal of Vocational Behavior, 35, 342-378.

Bryant, B.K., Zvonkovic, A.M., \& Reynolds, P. (2006). Parenting in relation to child and adolescent vocational development. Journal of Vocational Behavior, 69, 149-175.

Buyukgoze-Kavas, A., Duffy, R.D., \& Douglass, R.P. (2015). Exploring links between career adaptability, work volition, and well-being among Turkish students. Journal of Vocational Behavior, 90, 122-131. doi10.1016/j.jvb.2015.08.006

Cheung, F.M., Cheung, S.F., \& Fan, W. (2013). From Chinese to cross-cultural personality assessment: A combined emic-etic approach to study personality in culture. In M. Gelfand, Y.Y. Hong, \& C.Y. Chiu (Eds.), Advances in culture and psychology (vol. 3; pp. 117-180). Oxford, England: Oxford University Press.doi:https://doi.org/10.1093/ acprof:oso/9780199930449.003.0003

Cheung, F.M., Fan, W., \& Yao, D.J. (2012). Chinese personality and vocational behavior. In X. Huang \& M.H. Bond (Eds.), 
The handbook of Chinese organizational behavior: Integrating theory, research, and practice (pp. 359-379). Cheltenham, England: Edward Elgar.

Cheung, F.M., Wan, S.L.Y., Fan, W., Leong, F.T.L., \& Mok, P.C.H. (2013). Collective contributions to career efficacy in adolescents: A cross-cultural study. Journal of Vocational Behavior, 83, 237-244.

Crocetti, E., Rubini, M., Luyckx, K., \& Meeus, W. (2008). Identity formation in early and middle adolescents from various ethnic groups: From three dimensions to five statuses. Journal of Youth and Adolescence, 37, 983-996.

Diemer, M.A., \& Blustein, D.L. (2007). Vocational hope and vocational identity: Urban adolescents' career development. Journal of Career Assessment, 15, 98-118.

De Klerk, J.J. (2003). Motivation to work, work commitment and man's will to meaning. Unpublished doctoral dissertation, University of Pretoria, South Africa. (Order No. AAI0804314). Available from PsycINFO. (620240221; 200395003-001).

Duck, T., Middleton, J., Simpson, D., Thibodeaux, J., McDaniel, J., \& Buboltz, W. (2013). Family of origin and career development. In A. Di Fabio (Ed.), Psychology of counseling (pp. 125-169). Hauppauge, NY: Nova Biomedical Books.

Duffy, R.D., \& Dik, B.J. (2013). Research on calling: What have we learned and where are we going? Journal of Vocational Behavior, 83, 428-436. doi:10.1016/j.jvb.2013.06.006

Erikson, E. H. (1968). Identity: Youth and crisis. Oxford, England: Norton \& Co.

Fan, W., Cheung, F.M., Cheung, S.F., \& Leung, K. (2008). Gender difference of personality traits among Hong Kong secondary school students and their developmental analyses. Acta Psychologica Sinica, 40, 1002-1012. doi:https://doi.org/10.3724/SP.J.1041.2008.01002

Fan, W., \& Leong, F.T.L. (2016). Introduction: Career development and career intervention in Chinese contexts. The Career Development Quarterly, 64, 192-202.

Ferrari, L., Nota, L., \& Soresi, S. (2010). Time perspective and indecision in young and older adolescents. British Journal of Guidance and Counselling, 38, 61-82.

Frankl, V.E. (1992). Man's search for meaning: An introduction to logotherapy (4th ed.). Boston, MA: Beacon Press.

Gottfredson, L.S. (2002). Gotterfredson's theory of circumscription, compromise ans self-creation. In D. Brown and Associates (eds), Career choice and development (4th ed., pp. 85-148). San Francisco, CA: Jossey-Bass.

Guichard, J. (2015). From vocational guidance and career counseling to life design dialogues. In L. Nota \& J. Rossier (Eds.), Handbook of life design: From practice to theory and from theory to practice (pp. 11-25). Boston, MA: Hogrefe Publishing.

Hao, K., \& Wang, M. (2009). The only-child group and educational reform - A survey report on status of the only-child group in China. Educational Research, 2, 42-51.

Hartung, P.J. (2013). The life-span, life-space theory of careers. In S.D. Brown \& R.W. Lent (Eds.), Career development and counseling (2nd ed, pp. 83-113). Hoboken, NJ: John Wiley \& Sons.
Hartung, P.J., Lewis, D.M., May, K., \& Niles, S.G. (2002). Family interaction patterns and college student career development. Journal of Career Assessment, 10, 78-90.

Hesketh, B., \& Rounds, J. (1995). International cross-cultural approaches to career development. In W.B. Walsh \& P.J. Hartung (Eds.), Handbook of vocational psychology: Theory, research, and practice (pp. 369-390). Hillsdale, NJ: Lawrence Erlbaum Associates.

Hirschi, A. (2011). Vocational identity as a mediator of the relationship between core self-evaluations and life and job satisfaction. Applied Psychology: An International Review, 60, 622-644.

Hirschi, A. (2012). Vocational identity trajectories: Differences in personality and development of well-being. European Journal of Personality, 26, 2-12.

Ho, M.Y., Cheung, F.M., \& Cheung, S.F. (2010). The role of meaning in life and optimism in promoting well-being. Personality and Individual Differences, 48, 658-663. doi: 10.1016/j.paid.2010.01.008

Holland, J.J., Gottfredson, D.C., \& Power, P.G. (1980). Some diagnostic scales for research in decision making and personality: Identity, information, and barriers. Journal of Personality and Social Psychology, 39, 1191-1200.

Holland, J.L., Johnston, J.A., \& Asama, N.F. (1993). The Vocational Identity Scale: A diagnostic and treatment tool. Journal of Career Assessment, 1, 1-11.

Jiang, Y., \& Zhang, H. (2009). Analysis of cultural psychological differences between urban and rural Areas from the perspective of cultural psychology. Science of Social Psychology, $5,45-48,63$.

Jin, L., Watkins, D., \& Yuen, M. (2009). Personality, career decision self-efficacy and commitment to the career choices process among Chinese graduate students. Journal of Vocational Behavior, 74, 47-52. doi:10.1016/j.jvb.2008.10.002

Kagitcibasi, C. (2007). Family, self, and human development across cultures: Theory and applications (2nd ed.). Mahwah, NJ: Lawrence Erlbaum Associates.

Kwan, V.S.Y., Bond, M.H., Boucher, H.C., Maslach, C., \& Gan, Y. (2002). The construct of individuation: More complex in collectivist than in individualist cultures. Personality and Social Psychology Bulletin, 28, 300-310.

Kosine, N.R., Steger, M.F., \& Duncan, S. (2008). Purposecentered career development: A strengths-based approach to finding meaning and purpose in careers. Professional School Counseling, 12, 133-136. doi:10.5330/PSC.n.2010-12.133

Lent, R.W., Brown, S.D., \& Hackett, G. (1994). Toward a unifying social cognitive theory of career and academic interest, choice, and performance. Journal of Vocational Behavior, 45, 79-122. doi:http://doi.org/10.1006/jvbe.1994.1027

Li, L., \& Jia, Y. (2012). The analyses of parenting styles of primary school students in the urban and rural areas. Science of Social Psychology, 27, 107-111.

Li, M., Fan, W., Cheung, F.M., \& Wang, Q. (in press). Reciprocal associations between career self-efficacy and vocational identity: A three-wave longitudinal study. Journal of Career Assessment. 
Li, S., Zhu, C., \& Feldman, M.W. (2004). Gender differences in child survival in contemporary rural China: A county study. Journal of Biosocial Science, 36, 83-109.

Ma, S. (2017). The effect of parental warmth on proactive personality and school adjustment among college freshmen. China Journal of Health Psychology, 25, 1561-1563.

Marcia, J.E. (1966). Development and validation of ego-identity status. Journal of Personality and Social Psychology, 3,551558

Mayseless, O., \& Keren, E. (2014). Finding a meaningful life as a developmental task in emerging adulthood: The domains of love and work across cultures. Emerging Adulthood, 2, 63-73. doi: $10.1177 / 2167696813515446$

Meijers, F. (1998). The development of a career identity. International Journal for the Advancement of Counselling, 20, 191-207. doi:10.1023/A:1005399417256

Michael, R., Cinamon, R.G., \& Most, T. (2015). Career-related parental support of adolescents with hearing loss: Relationships with parents' expectations and occupational status. American Annals of the Deaf, 160, 60-72.

Min, D., \& Chen, C. (1991). Research on the correlation between the contact between the urban and rural audiences and the modern concepts. Journalism and Communication, 3, 1446.

Mortimer, J.T., Zimmer-Gembeck, M., Holmes, M., \& Shanahan, M.J. (2002). The process of occupational decision making: Patterns during the transition to adulthood. Journal of Vocational Behavior, 61, 439-465. doi:10.1006/jvbe.2002. 1885

National Bureau of Statistics of China. (n.d.). National data: 2017 Shanghai GDP. Retrieved from http://data.stats.gov.cn/ search/keywordlist2? keyword=2013\%20\%E4\%B8\%8A\% E6\%B5\%B7\%20gdp

Negru-Subtirica, O., Pop, E.I., \& Crocetti, E. (2015). Developmental trajectories and reciprocal associations between career adaptability and vocational identity: A three-wave longitudinal study with adolescents. Journal of Vocational Behavior, 88, 131-142.

Orkibi, H. (2010). Creative arts therapies students' professional identity and career commitment: A brief pilot study report. The Arts in Psychotherapy, 37, 228-232.

Pesch, K.M., Larson, L.M., \& Seipel, M.T. (2018). Career decision-making within the college social microcosm: Social value determinants and psychological needs. Journal of Career Assessment, 26, 291-307. doi:10.1177/ 1069072717692767

Organisation for Economic Co-operation and Development (OECD). (2012). PISA 2012 results. Retrieved from http:// www.oecd.org/pisa/keyfindings/pisa-2012-results.htm

Pizzorno, M.C., Benozzo, A., Fina, A., Sabato, S., \& Scopesi, M. (2014). Parent-child career construction: A narrative study from a gender perspective. Journal of Vocational Behavior, $84,420-430$.

Puffer, K.A. (1999). A study of collegians' family activities, roles, and interpersonal relations and their vocational identity, career choice commitment and decision making: An application of the developmental contextual framework.
Dissertation Abstracts International Section A: Humanities and Social Sciences, 59(12-A), 437.

Ryff, C.D., \& Singer, B. (1998). The contours of positive human health. Psychological Inquiry, 9, 1-28.

Salmela-Aro, K. (2009). Personal goals and well-being during critical life transitions: The four Cs - Channelling, choice, co-agency and compensation. Advances in Life Course Research, 14, 63-73.

Savickas, M.L. (1985). Identity in vocational development. Journal of Vocational Behavior, 27, 329-337.

Savickas, M.L. (2013). Career construction theory and practice. In R.W. Lent \& S.D. Brown (Eds.), Career development and counseling: Putting theory and research to work (2nd ed., pp.147-183). Hoboken, NJ: Wiley.

Savickas, M.L., \& Porfeli, E.J. (2012). Career Adapt-Abilities Scale: Construction, reliability, and measurement equivalence across 13 countries. Journal of Vocational Behavior, 80, 661-673.

Sawitri, D.R., Creed, P.A., \& Zimmer-Gembeck, M.J. (2015). Longitudinal relations of parental influences and adolescent career aspirations and actions in a collectivist society. Journal of Research on Adolescence, 25, 551-563.

Shoffner, M.F., \& Newsome, D.W. (2001). Identity development of gifted female adolescents: The influence of career development, age, and life-role salience. Journal of Secondary Gifted Education, 14, 201-211.

Silbereisen, R.K., Vondracek, F.W., \& Berg, L.A. (1997). Differential timing of initial vocational choice: The influence of early childhood family relocation and parental support behaviors in two cultures. Journal of Vocational Behavior, 50, 41-59.

Steger, M.F. (2009). Meaning in life. In S.J. Lopez, \& C.R. Snyder (Eds.), Oxford handbook of positive psychology (2nd ed, pp. 679-687). New York, NY: Oxford University Press.

Super, D.E. (1980). A life span, life space approach to career development. Journal of Vocational Behavior, 16, 282-298.

The World Bank. (2017). GDP per capita (current US\$). Retrieved from http://data.worldbank.org/indicator/NY. GDP.PCAP.CD

Urbanaviciute, I., Pociute, B., Kairys, A., \& Liniauskaite, A. (2016). Perceived career barriers and vocational outcomes among university undergraduates: Exploring mediation and moderation effects. Journal of Vocational Behavior, 92, 12-21.

Vondracek, F.W., \& Porfeil, E.J. (2003). The world of work and careers. In G.R. Adams \& M.D. Berzonsky (Eds.), Blackwell handbook of adolescence (pp. 100-108) New York, NY: Blackwell.

Wang, F., Oakland, T., \& Liu, D. (1992). Behavior problems exhibited by Chinese children from single- and multiplechild families. School Psychology International, 13, 313-321.

Wong, P.T. (1998). Implicit theories of meaningful life and the development of the Personal Meaning Profile. In P.T. Wong \& P. Fry (Eds.), The human quest for meaning (pp. 111-140). Mahwah, NJ: Erlbaum.

Wu, Y., \& Xu, X. (2014). Psychological analysis of the one-child 'Together' behavior. China Journal of Health Psychology, 22, $479-481$. 
Xin, T., Zhou, Z., Bray, M.A., \& Kehle, T.J. (2003). The structure of self-reported problem behaviors in Chinese children. Psychology in the Schools, 40, 19-33.

Yeager, D.S., \& Bundick, M.J. (2009). The role of purposeful work goals in promoting meaning in life and in schoolwork during adolescence. Journal of Adolescent Research, 24, 423-452.

Young, R.A., Marshall, S.K., \& Valach, L. (2007). Making career theories more culturally sensitive: Implications for counseling. The Career Development Quarterly, 56, 4-18. doi: 10.1002/j.2161-0045.2007.tb00016.x

Young, R.A., Valach, L., Ball, J., Turkel, H., \& Wong, Y.S. (2003). The family career development project in Chinese Canadian families. Journal of Vocational Behavior, 62, 287-304.
Yu, E.A., Chang, E.C., \& Kim, J.H.J. (2016). Asian American culturally relevant values as predictors of meaning in life in Asian and European American college students: Evidence for cultural differences? Asian American Journal of Psychology, 7, 159-166. doi:10.1037/aap0000042

Yuen, M., \& Yau, J. (2015). Relation of career adaptability to meaning in life and connectedness among adolescents in Hong Kong. Journal of Vocational Behavior, 91, 147-156. doi:10.1016/j.jvb.2015.10.003

Zhang, C., Hirschi, A., Herrmann, A., Wei, J., \& Zhang, J. (2017). The future work self and calling: The mediational role of life meaning. Journal of Happiness Studies, 18, 977991. doi:10.1007/s10902-016-9760-y 